\title{
Chloroquine ameliorates carbon tetrachloride-induced acute liver injury in mice via the concomitant inhibition of inflammation and induction of apoptosis
}

\author{
Chongshan Dai ${ }^{1}$ Xilong Xiao', Daowen $\mathrm{Li}^{1}$, Sun Tun'${ }^{1}$, Ying Wang ${ }^{1}$, Tony Velkov ${ }^{2,3}$ and Shusheng Tang ${ }^{1}$
}

\begin{abstract}
This is the first study to investigate the hepatoprotective effect of CQ on acute liver injury caused by carbon tetrachloride $\left(\mathrm{CCl}_{4}\right)$ in a murine model and the underlying molecular mechanisms. Ninety-six mice were randomly divided into the control $(n=8), \mathrm{CQ}(n=8), \mathrm{CCl}_{4}(n=40)$, and $\mathrm{CCl}_{4}+\mathrm{CQ}(n=40)$ treatment groups. In the $\mathrm{CCl}_{4}$ group, mice were intraperitoneally (i.p) injected with $0.3 \% \mathrm{CCl}_{4}\left(10 \mathrm{~mL} / \mathrm{kg}\right.$, dissolved in olive oil); in the $\mathrm{CCl}_{4}+\mathrm{CQ}$ group, mice were i.p injected with $\mathrm{CQ}$ at $50 \mathrm{mg} / \mathrm{kg}$ at 2, 24, and $48 \mathrm{~h}$ before $\mathrm{CCl}_{4}$ administration. The mice in the control and CQ groups were administered with an equal vehicle or CQ $(50 \mathrm{mg} / \mathrm{kg})$. Mice were killed at 2, 6, 12, 24, $48 \mathrm{~h}$ post $\mathrm{CCl}_{4}$ treatment and their livers were harvested for analysis. The results showed that CQ pre-treatment markedly inhibited $\mathrm{CCl}_{4}$-induced acute liver injury, which was evidenced by decreased serum transaminase, aspartate transaminase and lower histological scores of liver injury. $\mathrm{CQ}$ pretreatment downregulated the $\mathrm{CCl}_{4}$-induced hepatic tissue expression of high-mobility group box 1 (HMGB1) and the levels of serum HMGB1 as well as IL-6 and TNF-a. Furthermore, CQ pretreatment inhibited autophagy, downregulated NF-kB expression, upregulated p53 expression, increased the ratio of $\mathrm{Bax} / \mathrm{BCl}-2$, and increased the activation of caspase-3 in hepatic tissue. This is the first study to demonstrate that CQ ameliorates $\mathrm{CCl}_{4}$-induced acute liver injury via the inhibition of HMGB1-mediated inflammatory responses and the stimulation of pro-apoptotic pathways to modulate the apoptotic and inflammatory responses associated with progress of liver damage.
\end{abstract}

\section{Introduction}

Liver disease is a global health problem, in particular, acute liver injury is associated with high mortality rates ${ }^{1,2}$. The molecular processes underlying the pathogenesis of acute liver injury are known to involve a complex interplay of oxidative stress, apoptosis, autophagy, and

\footnotetext{
Correspondence: Tony Velkov (Tony.Velkov@unimelb.edu.au) or Shusheng Tang (tssfj@cau.edu.cn)

${ }^{1}$ College of Veterinary Medicine, China Agricultural University, No. 2 Yuanmingyuan West Road, Beijing 100193, P. R. China

${ }^{2}$ Department of Pharmacology \& Therapeutics, School of Biomedical Sciences, Faculty of Medicine, Dentistry and Health Sciences, The University of Melbourne, Parkville, Victoria 3010, Australia

Full list of author information is available at the end of the article.

Edited by A. Stephanou
}

necrosis ${ }^{3,4}$. Nuclear factor high-mobility group box 1 (HMGB1) appears to regulate oxidative stress, inflammatory signaling, and autophagy in hepatocytes ${ }^{5,6}$. Not surprisingly, HMGB1 plays a critical role in a wide array of liver diseases, such as liver ischemia-reperfusion injury, alcoholic liver disease, cholestasis, and drug-induced liver injury $^{7-10}$. The activation of HMGB1 is purported to regulate the NF- $\mathrm{kB}$ and mitogen-activated protein kinase (MAPK) pathways via the modulation of toll-like receptors (TLR) $-2,4$, and 9 , which in turn cascade to regulate the expression of inflammatory mediators, such as tumor necrosis factor (TNF)- $\alpha$ and interleukin (IL)-1 $\beta$, IL-6, and cyclooxygenase- $2^{11}$.

\section{(c) The Author(s) 2018}

(c) (i) Open Access This article is licensed under a Creative Commons Attribution 4.0 International License, which permits use, sharing, adaptation, distribution and reproduction in any medium or format, as long as you give appropriate credit to the original author(s) and the source, provide a link to the Creative Commons license, and indicate if changes were made. The images or other third party material in this article are included in the article's Creative Commons license, unless indicated otherwise in a credit line to the material. If material is not included in the article's Creative Commons license and your intended use is not permitted by statutory regulation or exceeds the permitted use, you will need to obtain permission directly from the copyright holder. To view a copy of this license, visit http://creativecommons.org/licenses/by/4.0/. 


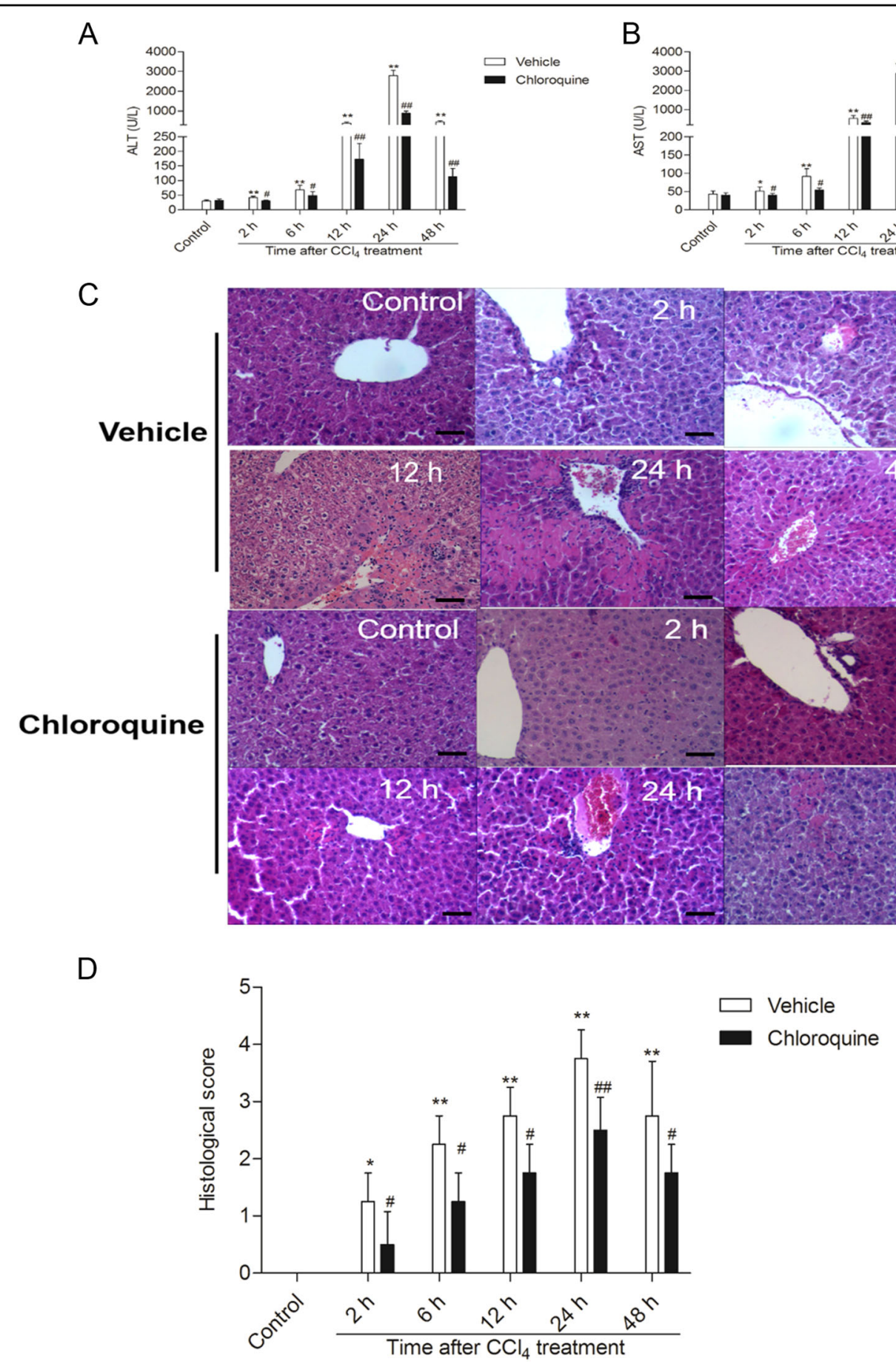

Fig. 1 Chloroquine pretreatment attenuates $\mathrm{CCl}_{4}$-induced acute liver injury in mice. a Time course of ALT serum levels $(n=8)$. $\mathbf{b}$ Time course of AST serum levels $(n=8)$. c Representative histopathological images of H\&E-stained liver sections from $\mathrm{CCl}_{4}$-treated mice pretreated with vehicle or $\mathrm{CQ}$. Bar $=100 \mu \mathrm{m}$. d The histological scores for liver sections from $\mathrm{CCl}_{4}$-treated mice pretreated with vehicle or CQ $(n=4)$. Data are presented as mean \pm SD. ${ }^{*} P<0.05$ and ${ }^{* *} P<0.01$, compared with the control group; ${ }^{\#} P<0.05$ and ${ }^{\# \#} P<0.01$, compared with the $C C l_{4}+$ vehicle group

Carbon tetrachloride $\left(\mathrm{CCl}_{4}\right)$-induced acute liver injury in murine models is widely used to investigate potential therapeutic strategies due to its similarities with acute chemical liver injury in humans ${ }^{3,12-15} \cdot \mathrm{CCl}_{4}$ is metabolized by the cytochrome P450 enzymes to form reactive intermediates, such as trichloromethyl-free radicals and 
peroxyl radical, which then initiate lipid peroxidation and cellular damage. Recently, Chen et al. demonstrated that hepatic HMGB1 expression played a critical role in $\mathrm{CCl}_{4}$ induced acute liver injury, and the blockade of HMGB1 (via a HMGB1-neutralizing antibody) could reduce oxidative stress and inflammation ${ }^{14}$. Similarly, $\mathrm{Li}$ et al. showed quercetin could reduce $\mathrm{CCl}_{4}$-induced liver fibrosis by inhibiting the expression of HMGB1 ${ }^{8}$.

Chloroquine (CQ) is an old antimalarial drug that has been repurposed as an antiinflammatory to treat rheumatoid arthritis, systemic lupus erythematosus, and Sjögren's syndrome ${ }^{16}$. There is a growing body of evidence suggesting that $C Q$ promotes apoptosis via the inhibition of autophagy ${ }^{17-20}$. A study from Yang et al. showed that CQ pretreatment could improve lipopolysaccharide (LPS)-induced mortality in mice by inhibiting the HMGB1 and NF-kB-mediated inflammatory pathways ${ }^{18}$. CQ has been shown to play dual roles in the process of liver ischemia reperfusion injury due to its antiinflammatory and pro-apoptotic activities ${ }^{19}$.

In the present study, we investigated the impact of $C Q$ pretreatment on $\mathrm{CCl}_{4}$-induced acute liver injury in a murine model. Our findings revealed CQ pretreatment improved $\mathrm{CCl}_{4}$-induced lethal liver failure death. The hepatoprotective effect of $\mathrm{CQ}$ involves the concomitant inhibition of HMGB1 and NF-kB-mediated inflammatory pathways, inhibition of autophagy, and the activation of pro-apoptotic pathways. These findings highlight the clinical potential of $C Q$ as a treatment strategy for acute liver injury in patients.

\section{Results}

Chloroquine pre-treatment attenuates $\mathrm{CCl}_{4}$-induced acute liver injury and mortality in mice

First, we assessed the time course of the hepatoprotective effect of CQ against $\mathrm{CCl}_{4}$-induced acute liver injury using the levels of serum ALT and AST, and liver histology as endpoints. Figure 1a, b shows the time course of the $\mathrm{CCl}_{4}$-induced changes of serum ALT and AST levels. Compared with the $\mathrm{CCl}_{4}+$ vehicle group, the mice from the $\mathrm{CCl} 4+\mathrm{CQ}$ group displayed significantly attenuated serum ALT and AST levels (all $P<0.05$ or 0.01 ). Mice from the CQ-only treatment group displayed comparable serum ALT and AST levels with the vehicle-treated control group.

Histological examination of the livers of mice from $\mathrm{CCl}_{4}+$ vehicle group revealed mild liver injury with some cellular necrosis around the blood vessels as early as $2 \mathrm{~h}$. More severe liver injury was evident at $24 \mathrm{~h}$, seen as large areas of extensive cellular necrosis with loss of hepatic architecture and inflammatory cell infiltration around the blood vessels (Fig. 1c). Compared with the vehicle treated control group, the histological scores for the $\mathrm{CCl}_{4}+$ vehicle group at $2,6,12,24$, and $48 \mathrm{~h}$ were all increased to
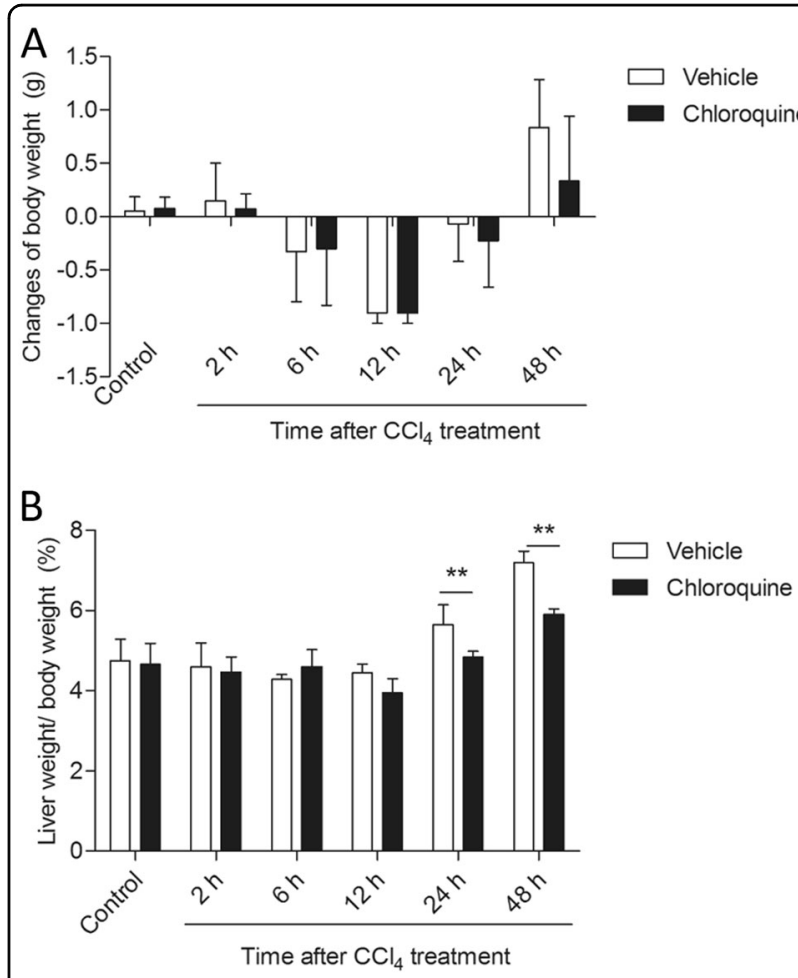

Fig. 2 The impact of chloroquine pretreatment on the changes of body weight and liver weight/body weight ratio following CCl4induced acute liver injury in mice. $\mathbf{a}$ The changes of body weight. $\mathbf{b}$ The changes of liver weight/body weight ratio (\%). Data are presented as mean $\pm \mathrm{SD}(n=8) .{ }^{* *} \mathrm{P}<0.01$, compared with the $\mathrm{CCl}_{4}$ alone group

$1.25,2.25,2.75,3.75$, and 2.75 (all $P<0.05$ or 0.01 ), respectively (Fig.1d). CQ pretreatment markedly attenuated $\mathrm{CCl}_{4}$-induced liver injury and significantly decreased the histological scores at 2, 6, 12, 24, and $48 \mathrm{~h}$ to $0.5,1.25,1.75,2.5$, and 1.75 , respectively (Fig. 1d). Compared with vehicle-treated control group, there were no abnormal histological changes in the livers of mice from the CQ-only treatment group. The animal's body weight showed time-dependent changes with the posttime of $\mathrm{CCl}_{4}$ treatment (Fig. 2). There were no marked changes between $\mathrm{CQ}$ and $\mathrm{CQ}+\mathrm{CCl}_{4}$ groups at 2, 6, 12, and $24 \mathrm{~h}$. However, at $48 \mathrm{~h}$, there was a significant decrease in the changes of body weight in the $\mathrm{CQ}+\mathrm{CCl}_{4}$ groups, compared with $\mathrm{CCl}_{4}$ group.

We further examined the protective role of $C Q$ pretreatment on $\mathrm{CCl}_{4}$-induced mortality in mice. The results documented in Fig. 3 showed that the 40\% survival rate seen with the $\mathrm{CCl}_{4}$ alone treated group improved to $80 \%$ at $24 \mathrm{~h}$ upon $\mathrm{CQ}$ pretreatment in the $\mathrm{CQ}+\mathrm{CCl}_{4}$ group.

\section{Chloroquine pre-treatment downregulates $\mathrm{CCl}_{4}$-induced hepatic HMGB1 expression and serum levels}

In comparison with mice from the vehicle-treated control group, the hepatic tissue expression of HMGB1 


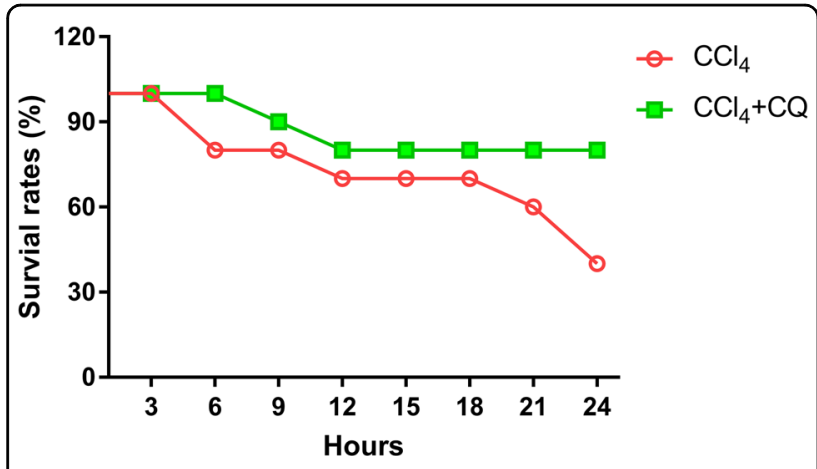

Fig. 3 Chloroquine pretreatment attenuates $\mathrm{CCl}_{4}$-induced lethal death in mice. In the $\mathrm{CCl}_{4}$ group, mice were ip injected with $2.5 \%$ $\mathrm{CCl}_{4}$ with or withoutpre-treatment of $\mathrm{CQ}$. The death ratios were recorded during $24 \mathrm{~h}$. ( $n=10$ per group)

and the serum HMGB1 levels were elevated ( 2.6- fold at $24 \mathrm{~h}$ ) in mice from the $\mathrm{CCl}_{4}+$ vehicle group (Fig. $4 \mathrm{a}, \mathrm{b}$ ). $\mathrm{CQ}$ pre-treatment markedly decreased both $\mathrm{CCl}_{4}$-induced hepatic HMGB1 expression and release of HMGB1 into the serum (Fig. 4a, b; Fig. 5). Furthermore, immunohistochemical staining revealed an increase in HMGB1 immunoreactivity and increased HMGB1 translocation from the nucleus to the cytoplasm in liver tissue sections of mice from the $\mathrm{CCl}_{4}+$ vehicle group. In comparison, HMGB1 expression in the cytoplasm of hepatocytes significantly decreased in the liver sections of mice from the $\mathrm{CCl}_{4}+$ CQ group (Fig. 4c).

\section{Chloroquine pretreatment inhibits $\mathrm{CCl}_{4}$-induced inflammatory responses}

To examine the impact of CQ pre-treatment on $\mathrm{CCl}_{4}$ induced liver inflammatory responses, we measured the serum levels and hepatic mRNA expression of TNF- $\alpha$ and IL-6 (Fig. 6). In comparison with mice from the vehicletreated control group, mice from the $\mathrm{CCl}_{4}+$ vehicle group showed significantly elevated serum levels and hepatic tissue expression of TNF- $\alpha$ and IL- 6 mRNAs (Fig. 6). CQ pre-treatment markedly decreased the levels of serum TNF- $\alpha$ (decreased to $\sim 2.5, \sim 3.4$, and $\sim 3.8 \mathrm{ng} /$ $\mathrm{mL}$, at 6,12 , and $24 \mathrm{~h}$, respectively; all $P<0.05$ and 0.01 ) and IL-6 (decreased to $\sim 39.1, \sim 60.2$, and $\sim 79.7 \mathrm{pg} / \mathrm{mL}$ at 6,12 , and $24 \mathrm{~h}$, respectively; all $P<0.01$ ) (Fig. $6 \mathrm{a}, \mathrm{b}$ ). Similarly, CQ pre-treatment significantly downregulated the $\mathrm{CCl}_{4}$-induced hepatic tissue mRNA expression levels of TNF- $\alpha$ and IL-6 (Fig. 6c, d).

Chloroquine pretreatment modulates the MAPK pathway, NF-KB pathway, autophagy, and apoptosis following $\mathrm{CCl}_{4}-$ induced acute liver injury in mice

$\mathrm{CCl}_{4}$ treatment significantly increased the expression of the autophagy markers Beclin1 and conversion of LC3II in hepatic tissue of mice at 2, 6, 12, and $24 \mathrm{~h}$ (Fig. 7). CQ pre-treatment upregulated the conversion of LC3II and downregulated expression of Beclin1. Notably, expression of Beclin1 and conversion of LC3II recovered at $48 \mathrm{~h}$ and no significant differences were evident between $\mathrm{CCl}_{4}$ alone and $\mathrm{CQ}$ pretreatment groups. For the biomarkers of the MAPK family (p-JNK, p-p38, p-Erk), $\mathrm{CCl}_{4}$ treatment increased the hepatic expression of p-JNK at 6,12 , 24 , and $48 \mathrm{~h}$ relative to the vehicle control. Similarly, the hepatic expression of p-p38 was increased at 2, 6, 12, and $48 \mathrm{~h}$, whereas the expression of p-Erk was increased at 12 and markedly at $48 \mathrm{~h}$. CQ pretreatment produced the opposite effect on p-JNK expression, wherein decreased levels were evident at $6,12,24$, and $48 \mathrm{~h}$ and increased levels were seen at $2 \mathrm{~h}$, relative to the $\mathrm{CCl}_{4}+$ vehicle treatment. In the case of p-Erk, CQ pre-treatment increased the expression at 2 and $6 \mathrm{~h}$ and markedly decreased levels at 24 and $48 \mathrm{~h}$. The expression of p38 following CQ pretreatment remained relative unchanged compared with the $\mathrm{CCl}_{4}+$ vehicle treatment. For the biomarkers of apoptosis, at 2, 6, 12, 24, and $48 \mathrm{~h}$ post $\mathrm{CCl}_{4}$ treatment, hepatic expression levels of $\mathrm{p} 53$, the ratio of $\mathrm{Bax} / \mathrm{Bcl}-2$, and cleaved caspase-3 significantly increased. CQ pre-treatment further upregulated the expression of these apoptotic biomarkers. In addition, $\mathrm{CCl}_{4}$ treatment upregulated the expression of NF- $\mathrm{kB}$ and I $\kappa B a$ at 24 and $48 \mathrm{~h}$. Whereas, CQ pretreatment markedly inhibited the expression of NF-kB and ІкBa. TUNELstained liver sections confirmed $\mathrm{CQ}$ pretreatment increased end stage of apoptosis in the liver tissue of mice, at $48 \mathrm{~h}$ relative to the vehicle treated control (Fig. 8). In line with the western blotting data, this effect was less pronounced at $24 \mathrm{~h}$.

\section{$\mathrm{CCl}_{4}$ blocks autophagy flux}

In the animal model, $\mathrm{CCl}_{4}$ treatment induced dynamic changes in p62 expression (Fig. 9a); At $12 \mathrm{~h}, \mathrm{p} 62$ protein levels increased $\sim 25$ fold, compared with the untreated control. Furthermore, we examined the role of autophagy using a HepG2 cell culture model. As shown in Fig. 8, in HepG2 cells that treated with $\mathrm{CCl}_{4}(10$ or $20 \mathrm{mM})$, LC3, p62, and HMGB1 protein levels significantly increased. CQ pretreatment further promoted the expression of LC3 and p62 proteins, but significantly inhibited the expression of HMGB1, compared with the $\mathrm{CCl}_{4}$ alone treated group (Fig. 9b).

Furthermore, to investigate which stage of the autophagic process is affected, a tandem human red fluorescent protein RFP-GFP-LC3 construct was transfected into the HepG2 cells. The results showed that HepG2 cells treated with $\mathrm{CCl}_{4}$ at $20 \mathrm{mM}$ and/or CQ $20 \mu \mathrm{M}$ for $12 \mathrm{~h}$ had mostly yellow/orange puncta indicative of the inhibition of autophagy flux by impairing autophagosome-lysosome fusion (Fig. 9c). 

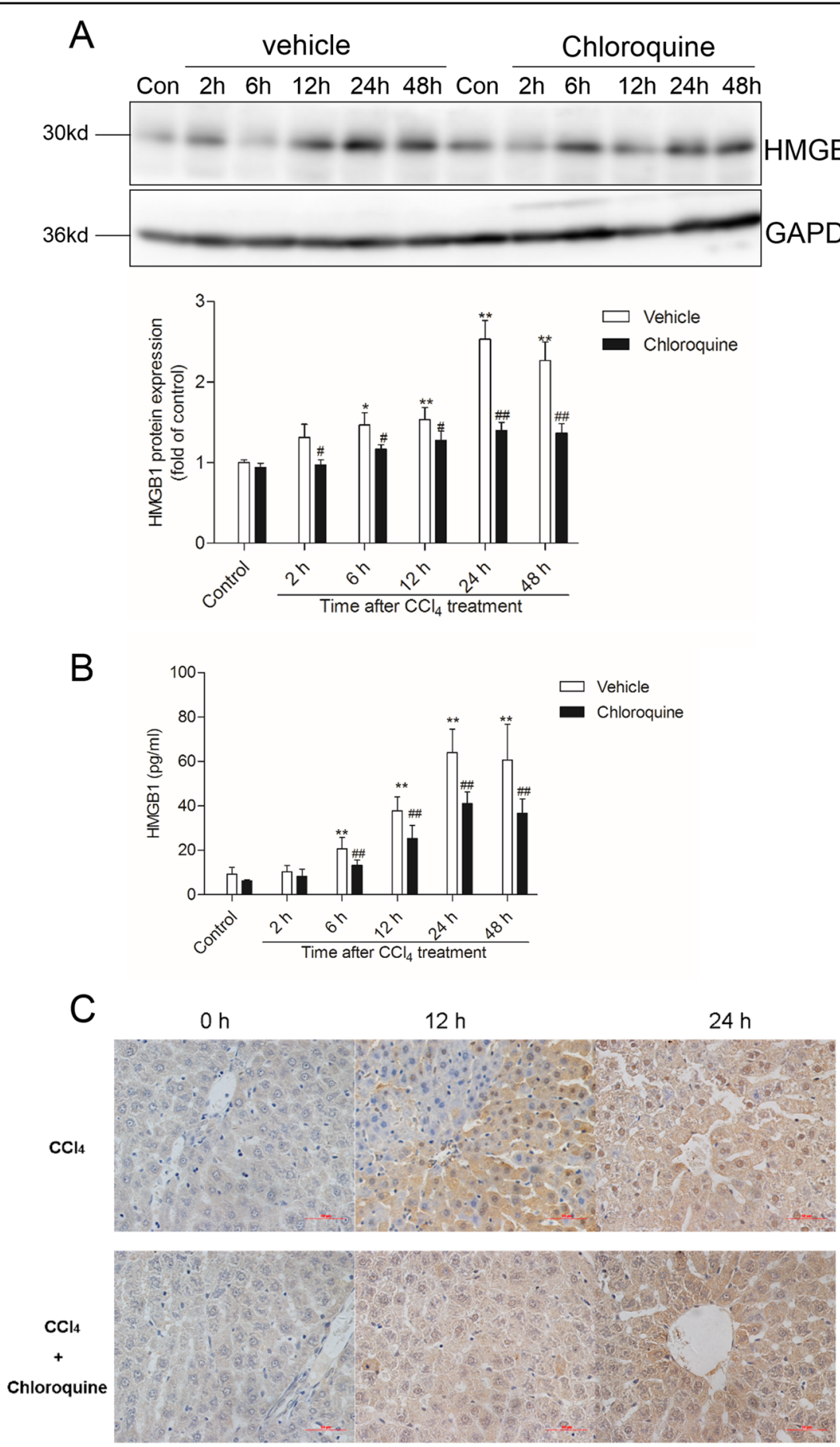

Fig. 4 Chloroquine pretreatment downregulates $\mathrm{CCl}_{4}$-induced hepatic HMGB1 expression and serum levels. a Western blotting analysis of HMGB1 protein expression in the liver tissue of mice from the vehicle and chloroquine (CQ) pretreated $\mathrm{CCl}_{4}$ groups $(n=4)$. b Serum HMGB1 levels measured by ELISA in mice from the vehicle and CQ pre-treatment groups $(n=8)$ at $24 \mathrm{~h}$. Data are presented as mean \pm SD. ${ }^{*} P<0.05$ and ${ }^{* *} P<0.01$, compared with the control group; ${ }^{\#} P<0.05$ and ${ }^{\# \#} P<0.01$, compared with the $\mathrm{CCl}_{4}+$ vehicle group. $\mathrm{c}$ Representative immunohistochemical results of hepatocytic HMGB1 protein expression at $24 \mathrm{~h}(n=4)$. Bar $=50 \mu \mathrm{m}$

\section{Discussion}

The global burden of liver disease is enormous, with an estimate of just over one million deaths annually ${ }^{21}$. This highlights the need for the discovery of effective "off-theshelf" hepatoprotective agents. In the current study, we provide demonstrable evidence that pre-treatment with 
the FDA approved drug CQ at $50 \mathrm{mg} / \mathrm{kg}$ for 2 days effectively attenuates $\mathrm{CCl}_{4}$-induced acute liver injury in a murine model (Fig. 1).

HMGB1 is an abundant and widely expressed DNAbinding protein that is involved in multiple pathological and physiological processes ${ }^{5,11,22}$. In the course of tissue injury, HMGB1 is secreted from activated immune cells or passively released into the extracellular milieu by dying or injured cells ${ }^{5,22}$. In the present study, we show that the hepatic tissue expression and serum levels of HMGB1 are

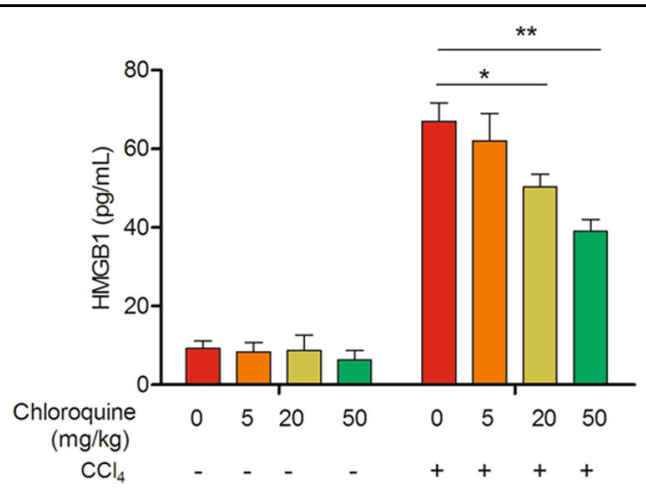

Fig. 5 Effect of different dose of chloroquine on the levels of serum HMGB1 in mice exposed with $\mathrm{CCl}_{4}$. Serum HMGB1 levels measured by ELISA in mice from the vehicle and CQ pre-treatment groups at $24 \mathrm{~h}(n=6)$. Data are presented as mean \pm SD. ${ }^{*} P<0.05$ and ${ }^{* *} P<0.01$, compared with the $\mathrm{CCl}_{4}$ alone group coincident with the severity of histopathological damage in the livers of mice treated with $\mathrm{CCl}_{4}$, and that this effect could be ameliorated by CQ pre-treatment (Figs. 1, 2). Notably, CQ pre-treatment can markedly improve high dose of $\mathrm{CCl}_{4}$-induced lethal death in mice (Fig. 3). In line with our findings, previous studies have shown that the systemic injection of a HMGB1-neutralizing antibody could effectively inhibit the inflammatory response and ameliorate $\mathrm{CCl}_{4^{-}}$and acetaminophen (APAP)-induced acute liver injury ${ }^{7,14}$. Since, HMGB1 is known to mediate inflammatory signaling related to the aforementioned pathological processess ${ }^{6-9,15,19,23-25}$, it represents an attractive antiinflammatory therapeutic target against acute liver injury ${ }^{6-9,11,18,25}$. In a mouse model of lethal sepsis, it has been demonstrated that $C Q$ inhibits HMGB1-mediated inflammation by blocking NF- $\mathrm{KB}$ activation, then improves LPS-induced lethal death in mice $^{18}$. NF- $\mathrm{kB}$ activation and nuclear translocation involves IкB kinase (IKK)-mediated phosphorylation IKB$\alpha$, which is then released from the NF- $\mathrm{B} B$ complex and is subsequently degraded. ${ }^{18}$ The degradation of IкB- $\alpha$ liberates NF- $\kappa B$, facilitating its nuclear translocation where it activates the expression of its proinflammatory cytokine target genes namely IL-1, IL-2, IL-6, and TNF- $\alpha .{ }^{11}$ In the present study, $\mathrm{CQ}$ pre-treatment markedly inhibited the decrease of IкB- $\alpha$ and activation of NF- $\kappa \mathrm{B}$ caused by $\mathrm{CCl}_{4}$, this in turn cascaded into decreased expression levels of IL- 6 and TNF- $\alpha$ in the liver tissue and their circulating serum levels in mice (Figs. 6, 7). Notably, the CQ
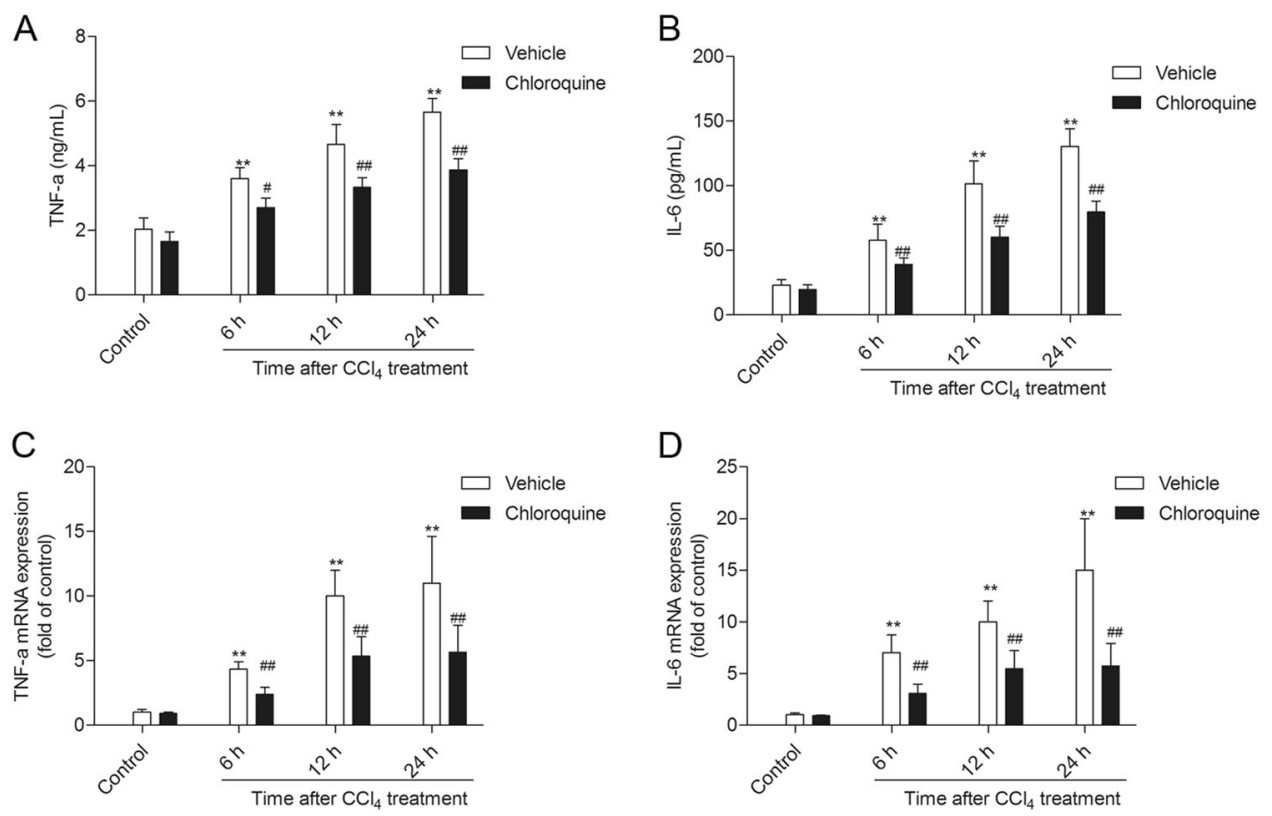

Fig. 6 Chloroquine pretreatment attenuates $\mathrm{CCl}_{4}$-induced inflammatory responses. a Serum levels of TNF-a. $\mathbf{b}$ Serum levels of IL-6. $\mathbf{c}$ Hepatic tissue expression levels of TNF-a mRNA. $\mathbf{d}$ Hepatic tissue expression levels of IL-6 mRNA. Data are presented as mean \pm SD $(n=8)$. ${ }^{*} P<0.05$ and ${ }^{* *} P<$ 0.01 , compared with the control group; ${ }^{\#} P<0.05$ and ${ }^{\# \#} P<0.01$, compared with the $\mathrm{CCl}_{4}+$ vehicle group 

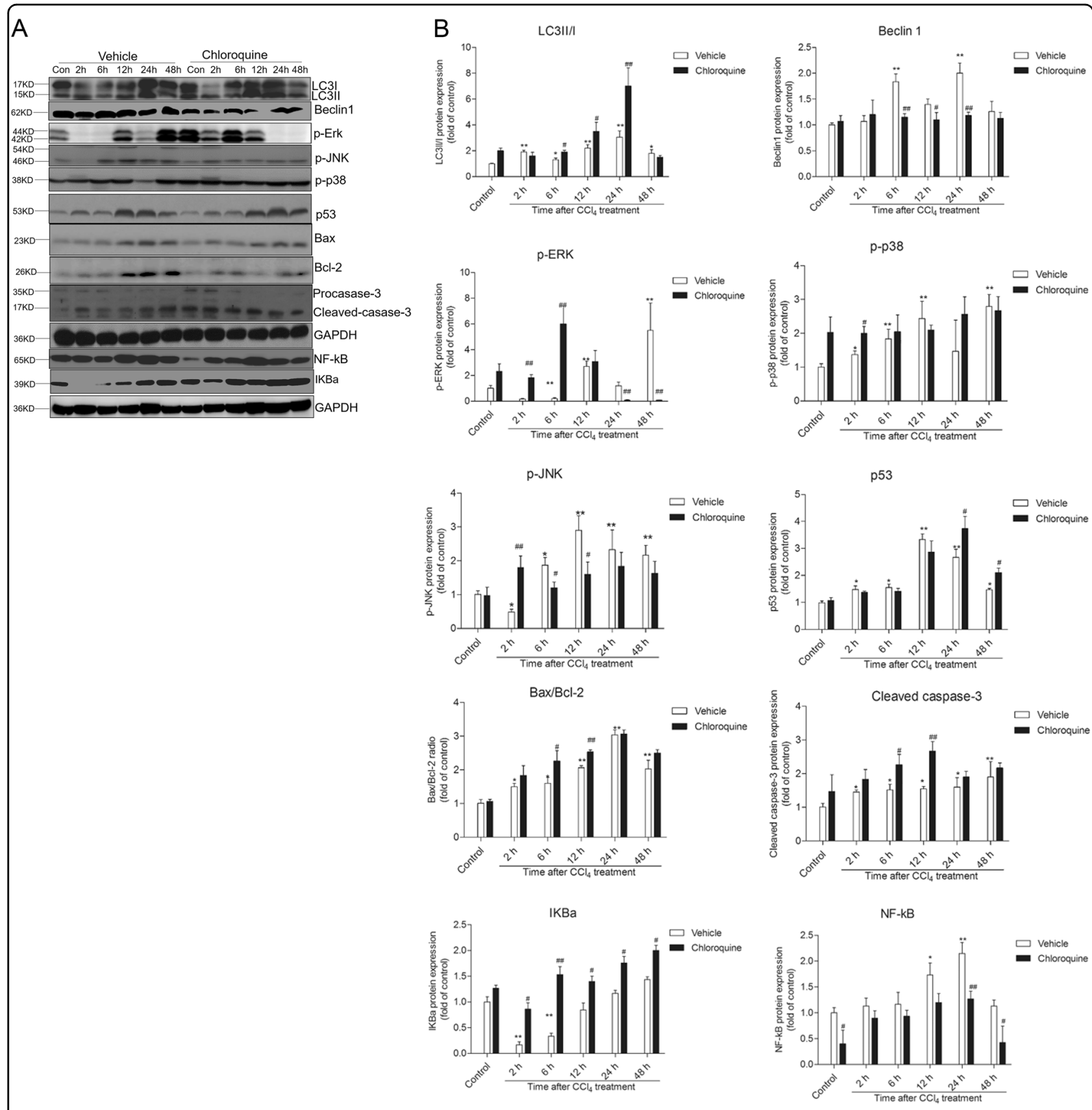

Fig. 7 The impact of chloroquine pretreatment on biomarkers of the MAPK family, NF-KB pathway, autophagy, and apoptosis following $\mathrm{CCl}_{4}$ - induced acute liver injury in mice. a Western blot analysis for $\mathrm{LC} 3$, Beclin1, phosphorylation (p)-Erk, p- JNK, p-p38, p53, Bax, BCl-2, NF-kB, IkBa,

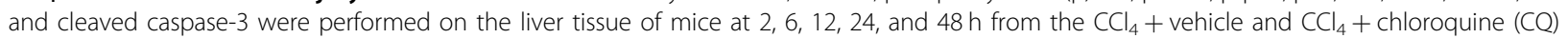
groups $(n=3)$. $\mathbf{b}$ The densitometric analysis of the bands was conducted using Image J. Data are shown as mean \pm SD $(n=3)$. ${ }^{*} P<0.05$ and ${ }^{* *} P<$ 0.01 , compared with the control group; ${ }^{\#} P<0.05$ and ${ }^{\# \#} P<0.01$, compared with the $\mathrm{CCl}_{4}+$ vehicle group

derivative hydroxyl-chloroquine has been shown to effectively attenuate streptozotocin-induced diabetic renal injury by inhibiting the release of inflammatory cytokines and attenuating apoptotic cell death ${ }^{26}$.

It is well known that the hepatic metabolism of $\mathrm{CCl}_{4}$ releases large amounts of reactive oxygen species (ROS), which in turn triggers apoptosis, autophagy, inflammation as well as tissue necrosis $3,14,27,28$. Not surprisingly, the mitochondrial pathway has been shown to play an important role in $\mathrm{CCl}_{4}$-induced apoptosis ${ }^{29}$. The mitochondrial pathway is regulated by a balancing act between the pro- and anti-apoptotic Bcl-2 family proteins, 


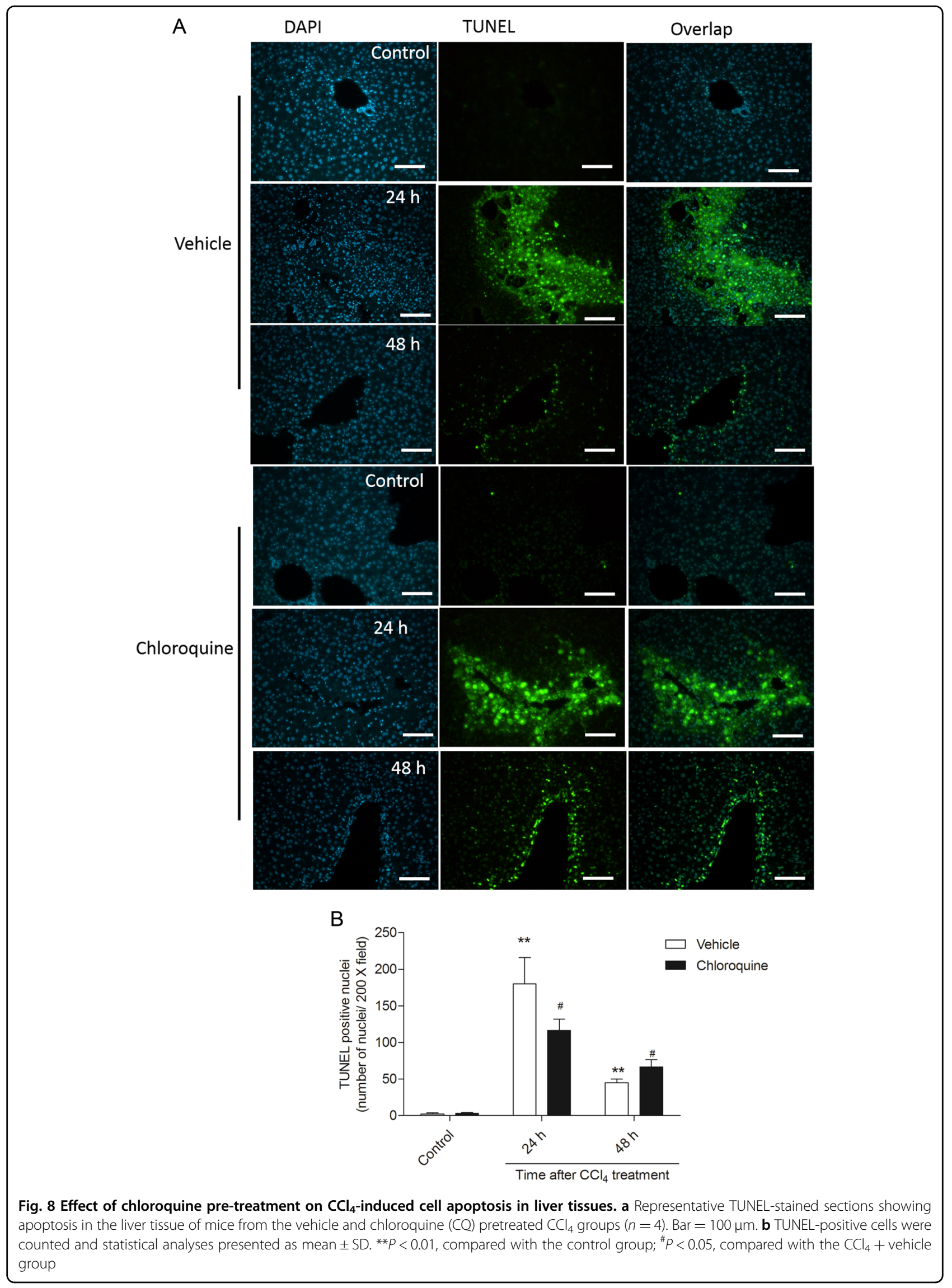




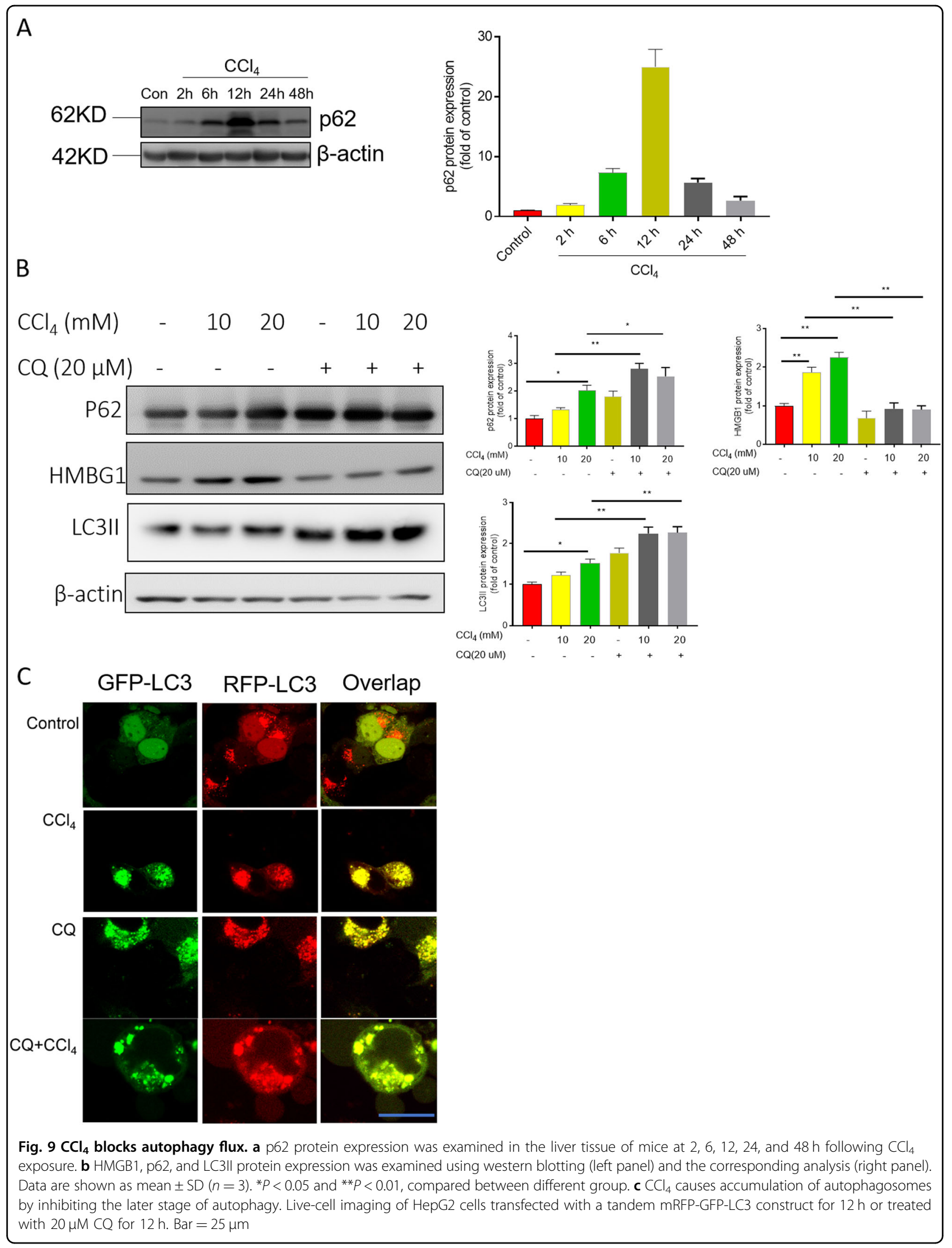


including Bax and $\mathrm{Bcl}-2^{30}$. Mitochondrial stress leads to the release of CytC into the cytoplasm, which in turn leads to the activation of caspase- 9 , and -3 , which triggers apoptosis $^{30}$. Moreover, p53 can also directly activate Bax, which permeabilizes mitochondria, causing mitochondrial $\mathrm{CytC}$ release and caspase activation, which again triggers apoptosis ${ }^{31}$. In the present study, we show that $\mathrm{CCl}_{4}$ treatment is followed by a time-dependent increase in the $\mathrm{Bax} / \mathrm{Bcl}-2$ ratio, p53 expression, and activation of caspase3 in hepatic tissue (Fig. 7); and these effects were further enhanced by CQ pre-treatment. The results from TUNEL staining (Fig. 7) at $48 \mathrm{~h}$ supported this phenomenon. Interestingly, we detected more TUNEL-positive cells at $24 \mathrm{~h}$ in the liver tissue of mice in the $\mathrm{CCl}_{4}$ alone treated group, than that in the CCl4 + CQ group (Fig. 8). Notably, DNA damage not only occurs during apoptotic cell death, but can also occur in the latter stages of necrotic cell death. ${ }^{32,33}$ This is where the TUNEL method has a serious drawback, in that it lacks the ability to discriminate apoptotic from necrotic cells given that the latter also have free DNA ends. ${ }^{32}$ Taken together, these results indicate that the observed increase in apoptotic cell death across the total cell population indirectly reflects the protective action of $\mathrm{CQ}$, which inhibits $\mathrm{CCl}_{4}$ induced necrotic cell death. The precise cell death dynamics that ensue during these treatments awaits further investigations.

One mechanism whereby the body copes with tissue damage on the cellular level is by employing a fine balance between autophagy and apoptosis ${ }^{31}$. In this elegant mechanism, autophagy acts to prevent or delay apoptotic cell death, and conversely when a cell cannot recover, apoptosis-associated caspase activation shuts off the autophagic process and kills the extensively damaged cell $^{34}$. LC3II and Beclin1 are markers of autophagic flux as they take part in the initiation and closure of the autophagic vesicle, respectively ${ }^{35}$. Our results demonstrate that increased hepatic autophagy follows $\mathrm{CCl}_{4}$-induced acute liver injury, which could be effectively attenuated by CQ pretreatment (Fig. 7). CQ appears to block autophagy flux by impairing autophagosome-lysosome fusion (Fig. 9). Notably, the inhibition of autophagy by CQ coincided with enhanced apoptosis at $6 \mathrm{~h}$ and $12 \mathrm{~h}$, which was evidenced by the significant increase in the $\mathrm{Bax} / \mathrm{Bcl}-2$ ratio and the expression of cleaved caspase-3 (Fig. 7), an indicator for initiation of apoptosis. These data suggest that CQ facilitates the elimination of extensively damaged cells from the liver tissue by promoting the activation of their apoptotic cell death pathways and concomitantly inhibiting autophagy. The knockdown of Beclin1 has been shown to attenuate HMGB1-mediated release of TNF- $\alpha$ and IL-6 in lethal sepsis via inhibiting NF-kB ${ }^{18}$. This would suggest that the downregulation of Beclin1 by CQ may partly contribute to its hepatoprotective effect via the inhibition of HMGB1-mediated inflammatory responses.

The MAPK, such as ERK, JNK, and p38, leads to the transcription of genes regulating cellular response to a plethora of stimuli such as proinflammatory mediators $^{34,36}$. It has been demonstrated that ERK, JNK, and p38 are involved in acute liver injury following treatment with hepatotoxins such as $\mathrm{CCl}_{4}$, APAP, or concanavalin $\mathrm{A}^{23,27,37}$. In the present study, the expression of p-JNK, $\mathrm{p}$ p38, and p-ERK showed dynamic changes during $48 \mathrm{~h}$ after $\mathrm{CCl}_{4}$ treatment. In the early phases of $\mathrm{CCl}_{4}$-induced acute liver injury (i.e., at $2 \mathrm{~h}$ and $6 \mathrm{~h}$ ), we observed a significant decrease in the expression of p-Erk, which was followed by increased expression levels at $48 \mathrm{~h}$, whereas CQ pretreatment produced the opposite effect (Fig. 7). Taken together, these data suggest that modulating of MAPK activation is also involved in the hepatic protective effects of CQ, which is in line with the proposed role of IL-6/Stat3 signaling for hepatoprotection ${ }^{38}$.

Taken together, our data indicated that CQ protects mice from $\mathrm{CCl}_{4}$-induced acute liver injury firstly, through the inhibition of hepatic HMGB1 expression and/or its systemic release, thereby preventing downstream inflammatory events; and secondly by inhibiting autophagy and promoting the apoptotic cells death of non-recoverable cells. Considering CQ is approved for human use, the next step towards the clinical translation of the data would be to perform scientifically based dosing studies of CQ in patients suffering from acute liver disease.

\section{Materials and methods \\ Chemicals and reagents}

$\mathrm{CCl} 4$ was purchased from Kaixing Chemical Industry Co., Ltd. (Tianjin, China). CQ (purity $\geq 98 \%$ ) was purchased from Sigma-Aldrich (St. Louis, MO, USA). Sodium dodecyl sulfonate (SDS), aprotinin, leupeptin, pepstatin A, and phenylmethylsulfonyl fluoride (PMSF) were purchased from AMRESCO Inc. (Solon, OH, USA). Dulbecco's modified Eagle's medium (DMEM) and fetal bovine serum (FBS) were from Life Technologies Corporation (Grand Island, NY, USA). All other chemicals were of the highest analytical grade available.

\section{Animals}

C57BL/6 mice (male, 6-8 weeks, 18-22 g) were purchased from Vital River Animal Technology Co., Ltd. (Beijing, China). Mice were housed in a room maintained at a temperature of $23 \pm 2{ }^{\circ} \mathrm{C}$ and relative humidity of $50 \pm$ $10 \%$ with a $12 \mathrm{~h}$ light-dark cycle. Mice were acclimatized for 1 week prior to use and had free access to food and water during the entire experiment. All animal experiments were approved by the Institutional Animal Care and Use Committee at the China Agricultural University. 


\section{Cell culture}

The human hepatoma HepG2 cell line (American Type Culture Collection (ATCC), HB-8065) was purchased from Cell Bank of Type Culture Collection of Chinese Academy of Sciences (Shanghai, China) and cultured in MEM supplemented with 10\% (v/v) heat-inactivated FCS, $110 \mathrm{mg} / \mathrm{L}$ sodium pyruvate, 100 units $/ \mathrm{mL}$ penicillin, and $100 \mu \mathrm{g} / \mathrm{mL}$ streptomycin. Cells were maintained in a humidified atmosphere of $95 \%$ air and $5 \% \mathrm{CO}_{2}$ at $37^{\circ} \mathrm{C}$.

\section{Experimental design}

To investigate the dose-dependent effect of CQ on CCl4-induced release of HMGB1, 48 mice were randomly divided into the following groups: control, CQ5, CQ20, CQ50, $\mathrm{CCl}_{4}, \mathrm{CCl}_{4}+\mathrm{CQ} 5, \mathrm{CCl}_{4}+\mathrm{CQ}_{20}$, and $\mathrm{CCl}_{4}+\mathrm{CQ} 50$ ( $n=6$ in each group). In the $\mathrm{CCl}_{4}$ group, mice were intraperitoneally (i.p) injected with $0.3 \%$ $\mathrm{CCl}_{4}(10 \mathrm{~mL} / \mathrm{kg}$, dissolved in olive oil $)$. In the $\mathrm{CCl}_{4}+$ CQ5, $\mathrm{CCl}_{4}+\mathrm{CQ} 20$ and $\mathrm{CCl}_{4}+\mathrm{CQ} 50$ groups, mice were at 5,20 , and $50 \mathrm{mg} / \mathrm{kg}$ at 2,24 , and $48 \mathrm{~h}$ prior to $\mathrm{CCl}_{4}$ administration. The mice in the control and CQ groups were administrated with an equal volume of vehicle or CQ $(5,20$, and $50 \mathrm{mg} / \mathrm{kg})$. After $24 \mathrm{~h}$, mice were anesthetized and blood was collected; the animals were then killed and their livers were harvested. Blood samples were centrifuged at $3000 \times g$ for $10 \mathrm{~min}$, and the serum was collected for examining the levels of serum HMGB1.

Then, 96 mice were randomly divided into the following groups: control, $\mathrm{CQ}, \mathrm{CCl}_{4}$, and $\mathrm{CCl}_{4}+\mathrm{CQ}$. In the $\mathrm{CCl}_{4}$ group, mice were i.p. injected with $0.3 \% \mathrm{CCl}_{4}(10 \mathrm{~mL} / \mathrm{kg}$, dissolved in olive oil). In the $\mathrm{CCl}_{4}+\mathrm{CQ}$ group, mice were i.p. injected with $\mathrm{CQ}$ at $50 \mathrm{mg} / \mathrm{kg}$ at 2, 24, and $48 \mathrm{~h}$ prior to $\mathrm{CCl}_{4}$ administration. The mice in the control and CQ groups were administrated with an equal volume of vehicle or CQ $(50 \mathrm{mg} / \mathrm{kg})$. At 2, 6, 12, 24, and $48 \mathrm{~h}$ after $\mathrm{CCl}_{4}$ administration, mice ( $n=8$ per time point) were anesthetized and blood was collected. Livers were divided into sections and fixed in $10 \%$ neutral buffered formalin at room temperature or snap frozen in liquid nitrogen and stored at $-80^{\circ} \mathrm{C}$.

To investigate the effect of $\mathrm{CQ}$ on $\mathrm{CCl}_{4}$-induced lethality, 20 mice were used and divided into the $\mathrm{CCl}_{4}$ treatment only group and $\mathrm{CCl} 4+\mathrm{CQ}$ group. The $\mathrm{CQ}$ treatment is same as that mentioned above. Mice were i.p. injected with $2.5 \% \mathrm{CCl}_{4}(10 \mathrm{~mL} / \mathrm{kg}$, dissolved in olive oil). Observation of lethality were subsequently performed performed over $24 \mathrm{~h}$.

\section{Serum transaminase (ALT), aspartate transaminase (AST) assays}

The levels of serum ALT and AST were examined by using an Automated Chemical Analyzer (Hitachi 7080, Hitachi High-Technologies Corporation) with the standard diagnostic kits (Shanghai Kehua Bio-engineering Co., Ltd., Shanghai, China).

\section{Histological examination of liver damage}

Livers were randomly selected from four mice and fixed in $10 \%$ neutral buffered formalin for $48 \mathrm{~h}$. The samples were dewaxed in xylene and rehydrated in a series of graded alcohols and then embedded in paraffin. The samples were sectioned at $4 \mu \mathrm{m}$ and stained with hematoxylin-eosin (H\&E) for light microscopic examination. To evaluate the degree of necrosis after acute liver injury, an injury grading score (Grade $0-4$ ) based on severity of necrotic lesions in the liver parenchyma were carried out as previously reported ${ }^{39}$. Each sample was independently scored by 3 pathologists who will be blind to the treatment and untreated control groups. The scoring system was as follows: Grade 0, no pathological change; Grade 1, presence of degenerated hepatocytes with only rare foci of necrosis; Grade 2, small area of mild centrilobular necrosis around the central vein; Grade 3, area of mild centrilobular necrosis severer than Grade 2; and Grade 4, centrilobular necrosis severer than Grade 3.

\section{Cytokine measurement}

The serum levels of TNF- $\alpha$, IL-6, and HMGB1 were measured using enzyme-linked immunosorbent assay (ELISA) kits according to the manufacturer's instructions (R\&D Systems, Minneapolis, MN, USA).

\section{Immunohistochemical staining}

The paraffin-embedded sections of liver tissues from the histopathological evaluations (above) were employed for immunohistochemical experiments. The embedded liver sections were deparaffinized and dehydrated in graded alcohol, then treated with $3 \% \mathrm{H}_{2} \mathrm{O}_{2}$ for 15 min, followed by microwave antigen retrieval for another $15 \mathrm{~min}$ in citrate buffer. Nonspecific antigens were blocked with 5\% goat serum for $30 \mathrm{~min}$. For HMGB1 staining, the specimens were incubated with a rabbit anti-mouse HMGB1 polyclonal antibody (1:200; ProteinTech Group, Inc., Chicago, IL, USA) at $4{ }^{\circ} \mathrm{C}$ overnight, followed by a $30 \mathrm{~min}$ incubation with a horseradish peroxidase (HRP)-conjugated goat anti-rabbit secondary antibody (Zhongshan Golden Bridge Biotechnology CO. LTD, China). Subsequently, the samples were stained with diaminobenzidine chromogen solution (Zhongshan Cambridge Reagent Company, Beijing, China), followed by hematoxylin, and mounted in xylene-based mountant.

\section{TUNEL assay}

Cell apoptosis in the liver tissue was detected using a terminal deoxynucleotidyl transferase-mediated dUTP nick-end labeling (TUNEL) assay kit, according to the manufacturer's protocol (Vazyme Biotech Co., Ltd, 
Nanjing, China). After TUNNEL labeling, the liver sections were counterstained with 4'-6-diamidino-2-phenylindole ${ }^{40}$ to label the nuclei. Images were observed under a fluorescence microscope (Leica Microsystems, Wetzlar, Germany).

\section{RFP-GFP-LC3 plasmid transfection}

HepG2 cells were transiently transfected with the RFPGFP-LC3 vector, kindly provided by Dr. Shen Zhang (UT southwestern medical Centre, Dallas, TX, USA) using Xtreme GENE HP DNA transfection reagents (Roche, Switzerland). After $48 \mathrm{~h}$, cells were treated with $\mathrm{CCl}_{4}$ at $20 \mathrm{mM}$ or CQ at $20 \mu \mathrm{M}$ for $12 \mathrm{~h}$, and the images were captured with a Zeiss Observer.Z1 microscope by using the Slidebook 4.2.0.11 computer program.

\section{Western blotting}

The liver tissue of three mice from each group were lysed using ice-cold lysis buffer $(100 \mathrm{mM}$ Tris- $\mathrm{HCl}, 2 \%$ [w/v] SDS, $10 \%$ [v/v] glycerol, $\mathrm{pH}$ 7.4); protease inhibitor cocktail $(1 \mathrm{mM}$ PMSF, $1 \mu \mathrm{g} / \mathrm{mL}$ aprotinin, $1 \mu \mathrm{g} / \mathrm{mL}$ leupeptin, and $1 \mu \mathrm{g} / \mathrm{mL}$ pepstatin $\mathrm{A}$ ) was added to the lysis buffer before treatment. The samples were ultrasonicated (5s ultrasonication and $6 \mathrm{~s}$ pause in each cycle for $5 \mathrm{x}$, power $30 \mathrm{~W}$ ) using an Ultrasonic Processor (Branson, MO, USA). The tissue lysates were centrifuged at $14,000 \times g$ for $15 \mathrm{~min}$ at $4{ }^{\circ} \mathrm{C}$, and the supernatants were collected. The protein concentration was measured using the BCA protein assay kit. Equal amounts of protein from each sample were resolved by SDS-PAGE and transferred to nitrocellulose membranes (Bio-Rad, Hemel Hempstead, UK). To investigate the role of autophagy, HepG2 cells were treated with CQ at $20 \mu \mathrm{M}$ at $2 \mathrm{~h}$ prior to $\mathrm{CCl}_{4}$ treatment $(10$ or $20 \mathrm{mM})$; after $12 \mathrm{~h}$, the cells were collected and the following protein levels were examined. The following primary antibodies were employed: primary rabbit antibodies against microtubule-associated protein 1 light chain 3 (LC3) (1:1000), Bax (1:1000), NF-kB (1:1000), IкBa (1:1000), Bcl-2 (1:1000) (ProteinTech Group, Inc., Chicago, IL, USA), phosphor (p)-extracellular signalregulated kinase (ERK) (Thr202/Tyr204) (1:1,000), p-p38 (Thr180/Tyr182), MAPK (1:1000), Beclin1 (1:1000), p-cJun N-terminal kinase (JNK) (Thr183/Tyr185) (1:1000) (Cell Signaling Technology, Beverly, MA, USA), caspase3, p62/SQSTM1 (1:5000), mouse monoclonal antibody against p53 (1:1000), and $\beta$-actin (1:1000), glyceraldehyde3-phosphate dehydrogenase (GAPDH) (1:1000) (Santa Cruz Biotechnology, CA, USA). Peroxidase-conjugated goat anti-rabbit or anti-mouse IgG (1:5000) (Santa Cruz Biotechnology, CA, USA) were employed as the secondary antibodies. The specific protein bands were visualized using the enhanced western luminescent detection kit (Vigorous Biotechnology, Beijing, China). The results were quantified by densitometry using Image J software, and the densitometry results were normalized relative to the GAPDH or $\beta$-actin bands.

\section{RNA extraction and real-time quantitative PCR}

Total RNA was isolated using the TRIzol extraction kits according to the manufacturer's instructions (Invitrogen Inc., Carlsbad, CA, USA). The quality of RNA was verified by evaluating the absorbance at $260 \mathrm{~nm}$ and $280 \mathrm{~nm}$. The production of cDNA was obtained from total RNA by using prime scriptTM RT reagent kit (TaKaRa). RT-PCR was performed with SYBR Green qPCR Kit (TaKaRa). The PCR conditions and primers used were as follows: TNF- $\alpha$ forward: $5^{\prime}$-GGC AGG TCT ACT TTG GAG TCA TTG C-3', TNF- $\alpha$ reverse: $5^{\prime}$-ACA TTC GAG GCT CCA GTG AAT TCG G-3', IL-6 forward: 5'-TGG AGT CAC AGA AGG AGT GGC TAA G-3', IL-6 reverse: $5^{\prime}$-TCT GAC CAC AGT GAG GAA TGT CCA C-3', GAPDH forward, 5'-ACA GTC CAT GCC ATC ACT GCC-3', GAPDH reverse: $5^{\prime}$-GCC TGC TTC ACC ACC TTC TTG-3'. PCR reactions were run under the following conditions: initial activation of Taq DNA polymerase at $95^{\circ} \mathrm{C}$ for $5 \mathrm{~min}, 40$ cycles of $30 \mathrm{~s}$ at $95^{\circ} \mathrm{C}$ for denaturing, $30 \mathrm{~s}$ at $60^{\circ} \mathrm{C}$ for annealing, and $30 \mathrm{~s}$ at $72^{\circ} \mathrm{C}$ for elongation. RT-PCR test was analyzed by ABI QuantStudio ${ }^{\mathrm{m}} 7$ detection system (Applied Biosystem, USA). All reactions were conducted in triplicate. GAPDH was used as an internal control, and fold change in gene expression was calculated using the threshold cycle method $\left(2^{-\Delta \Delta C T}\right)^{41}$.

\section{Statistical analyses}

All Data are presented as mean \pm SEM. The statistical analyses were performed using SPSS V16.0 (SPSS Inc., Chicago, IL, USA) and the differences between groups were compared with one-way ANOVA followed by Dunnett's multiple comparison procedure. A $P$-value $<$ 0.05 were considered as statistically significant.

\section{Acknowledgements}

This study was supported by the National Natural Science Foundation of China (Award number 31372486). T.V. is supported by a research grant from the National Institute of Allergy and Infectious Diseases of the National Institutes of Health (R01 Al111965). T.V. is also supported by the Australian National Health and Medical Research Council (NHMRC).

\section{Author details}

${ }^{1}$ College of Veterinary Medicine, China Agricultural University, No. 2 Yuanmingyuan West Road, Beijing 100193, P. R. China. ${ }^{2}$ Department of Pharmacology \& Therapeutics, School of Biomedical Sciences, Faculty of Medicine, Dentistry and Health Sciences, The University of Melbourne, Parkville, Victoria 3010, Australia. ${ }^{3}$ Drug Delivery, Disposition and Dynamics, Monash Institute of Pharmaceutical Sciences, Monash University, 381 Royal Parade, Parkville, Victoria 3052, Australia

Conflict of interest

The authors declare that they have no conflict of interest. 


\section{Publisher's note}

Springer Nature remains neutral with regard to jurisdictional claims in

published maps and institutional affiliations.

Received: 15 May 2018 Revised: 8 October 2018 Accepted: 10 October 2018 Published online: 26 November 2018

\section{References}

1. Taub, R. Liver regeneration: from myth to mechanism. Nat. Rev. Mol. Cell Biol. 5, 836-847 (2004).

2. Wu, Z., Han, M., Chen, T., Yan, W. \& Ning, Q. Acute liver failure: mechanisms of immune-mediated liver injury. Liver. Int. 30, 782-794 (2010).

3. Shi $\mathrm{H}_{\text {., }}$ et al. Augmenter of liver regeneration protects against carbon tetrachloride-induced liver injury by promoting autophagy in mice. Oncotarget 8, 12637-12648 (2017).

4. Jaeschke, H., McGill, M. R. \& Ramachandran, A. Oxidant stress, mitochondria, and cell death mechanisms in drug-induced liver injury: lessons learned from acetaminophen hepatotoxicity. Drug Metab. Rev. 44, 88-106 (2012).

5. Tang, D., Kang, R., Zeh, H. J. 3rd \& Lotze, M. T. High-mobility group box 1, oxidative stress, and disease. Antioxid. Redox Signal. 14, 1315-1335 (2011).

6. Andersson, U. \& Tracey, K. J. HMGB1 is a therapeutic target for sterile inflammation and infection. Annu. Rev. Immunol. 29, 139-162 (2011).

7. Lundback, P. et al. A novel high mobility group box 1 neutralizing chimeric antibody attenuates drug-induced liver injury and postinjury inflammation in mice. Hepatology 64, 1699-1710 (2016).

8. Li, X. et al. Quercetin attenuates the activation of hepatic stellate cells and liver fibrosis in mice through modulation of HMGB1-TLR2/4-NF-kappaB signaling pathways. Toxicol. Lett. 261, 1-12 (2016).

9. Ge, X. et al. High mobility group box-1 (HMGB1) participates in the pathogenesis of alcoholic liver disease (ALD). J. Biol. Chem. 289, 22672-22691 (2014).

10. Zhang, F., He, Y. \& Duan, Z. Changes of high mobility group box 1 in serum of pig acute hepatic failure model and significance. J. Huazhong. Univ. Sci. Technol. Med. Sci. 28, 52-55 (2008).

11. Ding J., Cui X., Liu Q. Emerging role of HMGB1 in lung diseases: friend or foe. J. Cell. Mol. Med. 21, 1046-1057 (2016).

12. Zhang, D. G. et al. Obeticholic acid protects against carbon tetrachlorideinduced acute liver injury and inflammation. Toxicol. Appl. Pharmacol. 314, 39-47 (2017).

13. Torres, L. R. et al. Pequi (Caryocar brasiliense Camb.) almond oil attenuates carbon tetrachloride-induced acute hepatic injury in rats: Antioxidant and antiinflammatory effects. Food Chem. Toxicol. 97, 205-216 (2016).

14. Chen, M. et al. High-mobility group box 1 exacerbates CCI(4)-induced acute liver injury in mice. Clin. Immunol. 153, 56-63 (2014).

15. Zhu, R. Z. et al. Protective effect of recombinant human IL-1Ra on CCl4induced acute liver injury in mice. World J. Gastroenterol. 16, 2771-2779 (2010).

16. Ben-Zvi, I., Kivity, S., Langevitz, P. \& Shoenfeld, Y. Hydroxychloroquine: from malaria to autoimmunity. Clin. Rev. Allerg. Immu 42, 145-153 (2012).

17. Zhang X. X., et al. Chloroquine enhanced the anticancer capacity of VNP20009 by inhibiting autophagy. Sci Rep. 6, 29774 (2016).

18. Yang, M. et al. Chloroquine inhibits HMGB1 inflammatory signaling and protects mice from lethal sepsis. Biochem. Pharmacol. 86, 410-418 (2013).

19. Fang, H., Liu, A., Dahmen, U. \& Dirsch, O. Dual role of chloroquine in liver ischemia reperfusion injury: reduction of liver damage in early phase, but aggravation in late phase. Cell Death Dis. 4, e694 (2013).

20. Cheng, Y., Ren, X., Hait, W. N. \& Yang, J. M. Therapeutic targeting of autophagy in disease: biology and pharmacology. Pharmacol. Rev. 65, 1162-1197 (2013).
21. Mokdad, A. A. et al. Liver cirrhosis mortality in 187 countries between 1980 and 2010: a systematic analysis. Bmc. Med. 12, 145 (2014).

22. Lotze, M. T. \& Tracey, K. J. High-mobility group box 1 protein (HMGB1): nuclear weapon in the immune arsenal. Nat. Rev. Immunol. 5, 331-342 (2005).

23. Gong G., et al. Protective effect of glycyrrhizin, a direct HMGB1 inhibitor, on focal cerebral ischemia/reperfusion-induced inflammation, oxidative stress, and apoptosis in rats. PLOS. ONE. 2014, 9, e89450.

24. Antoine, D. J. et al. High-mobility group box-1 protein and keratin-18, circulating serum proteins informative of acetaminophen-induced necrosis and apoptosis in vivo. Toxicol. Sci. 112, 521-531 (2009).

25. Lee, W. et al. Exendin-4 inhibits HMGB1-induced inflammatory responses in HUVECs and in murine polymicrobial sepsis. Inflammation 37, 1876-1888 (2014).

26. Abdel-Hamid, A. A. \& El-Firgany Ael, D. Hydroxychloroquine hindering of diabetic isletopathy carries its signature on the inflammatory cytokines. J. Mol. Histol. 47, 183-193 (2016).

27. Zhuang Y., Li Y., Li X. F., Xie Q., Wu M. Atg7 knockdown augments concanavalin A-induced acute hepatitis through an ROS-mediated p38/MAPK pathway. PLOS. ONE. 2016, 11, e149754.

28. Xie, J. et al. Dihydromyricetin alleviates carbon tetrachloride-induced acute liver injury via JNK-dependent mechanism in mice. World J. Gastroenterol. 21, 5473-5481 (2015).

29. Guo R., et al. Inhibition of caspase-9 aggravates acute liver injury through suppression of cytoprotective autophagy. Sci Rep-Uk 2016, 6, 32447.

30. Dai, C., Li, J., Tang, S., Li, J. \& Xiao, X. Colistin-induced nephrotoxicity in mice involves the mitochondrial, death receptor, and endoplasmic reticulum pathways. Antimicrob. Agents Chemother. 58, 4075-4085 (2014).

31. Wang, K. W. Autophagy and apoptosis in liver injury. Cell Cycle 14, 1631-1642 (2015).

32. Kelly, K. J., Sandoval, R. M., Dunn, K. W., Molitoris, B. A. \& Dagher, P. C. A novel method to determine specificity and sensitivity of the TUNEL reaction in the quantitation of apoptosis. Am. J. Physiol. Cell. Physiol. 284, C1309-1318 (2003).

33. Vogel, S. et al. Necrotic cell-derived high mobility group box 1 attracts antigen-presenting cells but inhibits hepatocyte growth factor-mediated tropism of mesenchymal stem cells for apoptotic cell death. Cell Death Differ. 22, 1219-1230 (2015).

34. Marino, G., Niso-Santano, M., Baehrecke, E. H. \& Kroemer, G. Self-consumption: the interplay of autophagy and apoptosis. Nat. Rev. Mol. Cell Biol. 15, 81-94 (2014).

35. Itakura, E. \& Mizushima, N. Characterization of autophagosome formation site by a hierarchical analysis of mammalian Atg proteins. Autophagy 6, 764-776 (2010).

36. Ni, H. M., Bockus, A., Boggess, N., Jaeschke, H. \& Ding, W. X. Activation of autophagy protects against acetaminophen-induced hepatotoxicity. Hepatology 55, 222-232 (2012).

37. Cubero, F. J. et al. Combined activities of JNK1 and JNK2 in hepatocytes protect against toxic liver injury. Gastroenterology 150, 968-981 (2016).

38. Taub, R. Hepatoprotection via the IL-6/Stat3 pathway. J. Clin. Invest. 112, 978-980 (2003).

39. Li, S. Q. et al. Proper heat shock pretreatment reduces acute liver injury induced by carbon tetrachloride and accelerates liver repair in mice. J. Toxicol. Pathol. 26, 365-373 (2013).

40. Narala, V. R. et al. Curcumin is not a ligand for peroxisome proliferatoractivated receptor-gamma. Gene. Ther. Mol. Biol. 13, 20-25 (2009).

41. Dai, C., Tang, S., Velkov, T. \& Xiao, X. Colistin-Induced apoptosis of neuroblastoma-2a cells involves the generation of reactive oxygen species, mitochondrial dysfunction, and autophagy. Mol. Neurobiol. 53, 4685-4700 (2016). 